\title{
Synthesis and characterization of poly(4-vinyl pyridine-co- styrene)/FHAP nanocomposite, and its biomedical application
}

\author{
C. P. Dhanalakshmi $\cdot$ L. Vijayalakshmi • \\ V. Narayanan
}

Received: 8 April 2012/Accepted: 2 November 2012/Published online: 11 January 2013

(C) The Author(s) 2013. This article is published with open access at Springerlink.com

\begin{abstract}
Among the composite materials, ceramic/ polymer possesses significant advantages of high mechanical reliability and excellent biocompatibility for applications in load-bearing areas. In this work, PVPCS(Poly (4-vinyl pyridine-co-styrene))/FHAp nanocomposites of varying weight percentages were synthesized and characterized physical-chemically by XRD, FTIR, ${ }^{31} \mathrm{P}$ NMR, TGA, DTA, and FE-SEM and biologically by antimicrobial and anti-inflammatory assays for evaluating their potential use for biomedical applications. The results indicated that the size and crystallinity of FHAp nanoparticles decrease with increase in PVPCS concentration in the composite. SEM confirmed the presence of FHAp nano rod crystals in PVPCS matrix. The nano PVPCS20/FHAp demonstrated the highest antifungal and antibacterial activity and favorable inhibition of human cell hemolysis. The designed PVPCS/FHAp nanocomposites constitute promising candidates for biomedical applications.
\end{abstract}

Keywords Fluorinated hydroxyapatite .

Nanocrystalline $\cdot$ Nanocomposite .

PVPCS[poly (4-vinylpyridine-co-styrene)]

C. P. Dhanalakshmi · V. Narayanan $(\bowtie)$

Department of Inorganic Chemistry, School of Chemical

Sciences, University of Madras, Guindy Maraimalai Campus,

Chennai 600025, Tamil Nadu, India

e-mail: vnnara@yahoo.co.in

L. Vijayalakshmi

Department of Chemistry, S.D.N.B. Vaishnav College

for Women, Chrompet, Chennai 600044, India

\section{Introduction}

The past three decades have witnessed a significative increase in the use of biomaterials for bone-related surgical applications. In certain applications involving artificial bones and teeth, the thrust for high biocompatibility, bioactivity, ability for biodegradation, and mechanical properties equivalent to bone and teeth is ensured from the clinical experience. However, the biodegradation of HAp under physiological conditions makes the interface between HAp and bone unstable (Bertinetti et al. 2007). Fluoridated hydroxyapatite (FHAp), where $\mathrm{F}^{-}$partially replaces the $\mathrm{OH}^{-}$in the hydroxyapatite, is considered as an alternative material for bone repair due to its low solubility and good biocompatibility (Boissiere et al. 2006; Bose and Saha 2003; Chen et al. 2004). Many researchers have also demonstrated that fluoride ions in the culture medium stimulated osteoblastic activities in terms of cell proliferation and differentiation (Chen et al. 2007; Choi and Kumta 2006; Darder et al. 2006; Degirmenbasi et al. 2006). The amount of fluoride ions released from fluoridated hydroxyapatite (FHAp) could be controlled by tailoring the fluoride content in FHAp (Ding et al. 2007). The higher the level of fluoridation, the more fluoride ions released. As a result, besides its high thermal and chemical stability (Boissiere et al. 2006; Gandhidasan et al. 1991), FHAp is considered as a promising implant material due to its great biological potential (Huang et al. 2007). However, high $\mathrm{F}^{-}$ concentration in bone can also lead to severe adverse effects such as osteomalacia (Joseph and Tanner 2005). Therefore, it is necessary to optimize the $\mathrm{F}^{-}$content in fluoride-substituted hydroxyapatite so as to achieve the maximum bioactivity of the material. However, the pure FHAp is only suitable to the repair of non-load bearing bones because of its fragility, low mechanical strength, 
easy rupturing, and weak fatigue resistance. On the other hand, pure FHAp could not degrade in the human body. These disadvantages of FHAp ceramic impede its further clinical application. Accordingly, an ideal material was needed to toughen the FHAp ceramic to better meet the clinical demands in both biological characteristics and mechanical properties. To solve the problem, incorporation of FHAp into polymer matrix has been carried out to increase osteoconductivity and biodegradability with significant enhancement of mechanical strength. Poly-4-vinyl pyridine-co-styrene (PVPCS) can be utilized in combination with FHAp to meet these requirements.

An extensive study has been made on both natural (collagen, gelatin, silk fibroin) and synthetic (polyethylene, polyamide, chitosan, polystyrene, poly(vinyl alcohol), poly(ethylene glycol) and poly(etheretherketone) polymers to overcome the mechanical problems associated with bio ceramics in bone tissue engineering applications (Joseph and Tanner 2005; Kannan and Ferreira 2006; Kannan et al. 2006; Kawagoe et al. 2000). Among the abovementioned polymers, PVPCS remains one of the widely used polymer group of biomaterials applied to medical implants. This wide range of versatility is utilized in terms of tailoring their applications such as tissue scaffolding (Kokubo and Takadama 2006), artificial cartilage (Komlev et al. 2003), and biodegradable scaffolds (Lak et al. 2008; Li et al. 2008, 2009). With the superior combination of the synergic effect and biocompatible FHAp and the adjustable biodegradability of polymer matrix, FHAp nano rod embedded PVPCS composites were prepared under controlled environment. The present work carried out elaborates on synthesis of nanostructured FHAp by wet chemical method using calcium hydroxide, ammonium fluoride, and diammonium hydrogen phosphate as starting materials and synthesis of nanostructured PVPCS/FHAp composite by freeze-drying method using synthetic nano FHAp as starting materials with the aid of PVPCS. In this paper PVPCS/ FHAp nanocomposites of varying compositions were prepared. While the previously studied supports offer several advantages, fluorinated hydroxyapatite is unique in its bioactivity. In the present work we tried to synthesize, characterize, and evaluate the invitro study of antimicrobial and anti-inflammatory effect of the PVPCS/FHAp nanocomposite materials (Magaldi et al. 2004).

\section{Experimental design}

\section{Materials}

The raw materials required to start the processing of the composite were analytical grade calcium hydroxide $\left[\mathrm{Ca}(\mathrm{OH})_{2}\right]$, ammonium fluoride and diammonium hydrogen phosphate $\left[\left(\mathrm{NH}_{4}\right)_{2} \mathrm{HPO}_{4}\right]$ obtained from Merck (India), and PVPCS purchased from Loba (India). Doubly distilled water was used as the solvent.

Methods

\section{Synthesis of nano FHAp}

A $0.25-\mathrm{M}$ ammonium fluoride solution and $0.3 \mathrm{M}$ diammonium hydrogen phosphate (Merck India) solution were prepared separately and these two solutions were added to a $0.3-\mathrm{M}$ calcium hydroxide aqueous suspension and stirred vigorously. These reactants in aqueous medium with a $\mathrm{pH}$ of 11 were immediately subjected to microwave irradiation for about $30 \mathrm{~min}$ in a domestic microwave oven (Samsung, $1100 \mathrm{~W}$ power). The precipitate was thoroughly washed with distilled water to remove impure ions $\left(\mathrm{NH}_{4}{ }^{+}\right)$. The product obtained after filtration was oven-dried overnight at $90{ }^{\circ} \mathrm{C}$ and the flakes were powdered using an agate mortar and pestle.

\section{Synthesis of PVPCS/FHAp nanocomposites}

The PVPCS/FHAp nanocomposites were coded as nano PVPCS20/FHAp, nano PVPCS40/FHAp, nano PVPCS60/ FHAp, and nano PVPCS80/FHAp where number denotes the wt \% of PVPCS matrix used in the processing. Water was used as the solvent to prepare the polymer solution. PVPCS was dissolved using magnetic stirrer for $3 \mathrm{~h}$ and the polymer solution was left overnight in room temperature to remove the air bubbles trapped in the viscous solution. Then suitable amount of FHAp was dispersed in deionised water by 30-min ultrasonication (METAL POWER ANALYTICAL (I) PVT. LTD. Maharashtra, India). Ultrasonication was necessary to avoid agglomeration of ceramic powder and to achieve proper dispersion. FHAp in water was mixed with polymer solution under agitation. The homogeneously mixed solution is immediately taken to deep freeze (AC MAS Technology (p) Ltd,India) at $-18^{\circ} \mathrm{C}$. After $48 \mathrm{~h}$ of freezing the samples were freeze dried.

\section{Physical-chemical characterization}

The prepared samples were studied by Fourier Transform Infrared Spectroscopy (FTIR) using a Schimadzu FT-IR 300 series instrument (Shimadzu Scientific Instruments, USA). The FTIR spectra were obtained over the region $450-4,000 \mathrm{~cm}^{-1}$ in pellet form for $1 \mathrm{mg}$ powder samples mixed with $200 \mathrm{mg}$ spectroscopic grade $\mathrm{KBr}$ (Merck, India). Spectra were recorded at $4 \mathrm{~cm}^{-1}$ resolution averaging 80 scans. The structure of the samples was analyzed by X-Ray Diffraction (XRD) using a Rich Siefert 3000 diffractometer (Seifert, Germany) with $\mathrm{Cu}-\mathrm{K} \alpha_{1}$ radiation 
$(\lambda=1.5418 \AA)$. The diffraction peak at $25.9^{\circ}$ was chosen for calculation of the crystallite size by Scherrer's formula since it is sharper and isolated from others. This peak assigns to (002) Miller's plane family and shows the crystal growth along the axis of FHAp crystalline structure. The morphology of the materials was analyzed by FieldEmission Scanning Electron Microscopy (FE-SEM) using a HITACHI S600N scanning electron microscopy (HITACHI High Tech, Japan). For the elemental analysis the electron microscope was equipped with an energy-dispersive X-ray attachment (EDAX). Thermo gravimetric analysis (TGA) coupled with differential thermal analysis (DTA) of the material was performed (STA 1500, PL Thermal Science, ) between 35 and $1,400{ }^{\circ} \mathrm{C}$ in air at a heating rate of $20 \mathrm{~K}$ per minute to monitor the weight loss of organic residues. ${ }^{31} \mathrm{P}-\mathrm{MAS}-\mathrm{NMR}$ spectra were recorded on a Bruker MSL 300 spectrometer (HORIBA Scientific USA) equipped with an Andrew type rotor rotating at a frequency of $10 \mathrm{kHz}$.

\section{Antimicrobial characterization}

For inoculum preparation, human pathogenic fungi from American Type Culture Collection (ATCC, USA), Candida albicans (ATCC 90028), and Candida paratrophicalis (ATCC 42618) were used in the antifungal activity test. In the antibacterial susceptibility test, fresh bacterial colonies from ATCC (USA) of the five pathogenic strains (Staphylococcus aureus [ATCC 12600], Escherichia coli [ATCC 11775], Salmonella typi [ATCC 700931], Vibrio cholerae [ATCC 39315], and Klebsiella pneumonia [ATCC 13883]) were inoculated to Tryptic soy or Brain Heart Infusion broth (EMD chemicals USA) and incubated at $37{ }^{\circ} \mathrm{C}$ during a time period of 22-24 h. Turbidity was adjusted with sterile broth so as to correspond to the Mc Farland 0.5 barium sulfate method, where the standard equivalent to $1.5 \times 10^{6}$ Colony Forming Units $(\mathrm{CFU}) / \mathrm{ml}$ in a $1: 100$ dilution of a suspension of turbidity. This is prepared by adding $0.5 \mathrm{ml}$ of $1.175 \% \mathrm{w} / \mathrm{v}(0.048 \mathrm{~m})$ hydrate $\left(\mathrm{BaCl}_{2} \cdot 2 \mathrm{H}_{2} \mathrm{O}\right)$ to $99.5 \mathrm{ml}$ of $1 \% \mathrm{w} / \mathrm{v}(0.36)$ sulfuric acid (Merk, India).

Antifungal and antibacterial activities of the PVPCS/ FHAp nanocomposites were tested by the well diffusion method using Sabouraud dextrose agar and Muller Hinton agar (Sigma Aldrich, India). The radial growth of the colony was analyzed on completion of the incubation, and the mean diameter for each composite at concentrations of $250,500,750$, and 1,000 $\mu \mathrm{g} / \mathrm{ml}$ were recorded. The average percentage inhibition of the bacterial growth medium was compared using the Vincent equation $\mathrm{I}=100 /(C-T) /$ $C$, where $I=$ percentage inhibition, $T=$ average diameter of the bacterial growth on the tested plates, and $C=$ average diameter of the growth on the control plates.
Stock solutions of tested compounds were prepared in dimethyl sulfoxide (Sigma-Aldrich, India).

\section{Anti-inflammatory activity test by HRBC membrane stabilization method}

The human red blood cell (HRBC) membrane stabilization has been used as method to study the anti-inflammatory activity. After approbation of Human Research Ethics Committee and signed consent form, blood samples collected from healthy volunteer were used in this test. The harvested blood was mixed with equal volume of sterilized Alsever solution (2\% dextrose, $0.8 \%$ sodium citrate, $0.05 \%$ citric acid and $0.42 \%$ sodium chloride in water). The blood was centrifuged at 3,000 rpm and packed cell were washed with isosaline $(0.85 \%, \mathrm{pH} 7.2)$ and a $10 \%$ $(\mathrm{v} / \mathrm{v})$ suspension was made with isosaline. The assay mixture contained the drug (various concentrations $\mathrm{g} / \mathrm{ml}$ ), $1 \mathrm{ml}$ of phosphate buffer $(0.15 \mathrm{M}, \mathrm{pH} 7.4), 2 \mathrm{ml}$ of hyposaline $(0.36 \%)$, and $0.5 \mathrm{ml}$ of HRBC suspension. Diclofenac (Sigma Aldrich, India) was used as reference drug. Instead of hyposaline $2 \mathrm{ml}$ of distilled water was used in the control. All the assay mixture was incubated at $37^{\circ} \mathrm{C}$ for $30 \mathrm{~min}$ and centrifuged. The hemoglobin content in the supernatant solution was estimated using spectrophotometer at $560 \mathrm{~nm}$ (Shimadzu Scientific Instruments, USA). The percentage protection was calculated by assuming the hemolysis produced in the presence of distilled water to be $100 \%$. The percentage of hemolysis was calculated using the following formula:

$$
\begin{aligned}
\% \text { Protection }= & \frac{100-\text { Optical density of drug treated sample }}{\text { Optical density of control }} \\
& \times 100
\end{aligned}
$$

\section{Results and discussion}

XRD analysis

The XRD patterns of nano FHAp and nano PVPCS/FHAp composites were taken. The patterns indicate the presence of amorphous FHAp. The broad peaks reveal that the particles sizes are very small in the range of $35-50 \mathrm{~nm}$. The reflection planes corresponding to the characteristic XRD spectral peaks of pure nanoHAp and PVPCS/FHAp nanocomposites are shown in Fig. 1. The observed diffraction peaks are identified by standard JCPDS file (no. 87-2462) and are assigned as crystalline FHAp. The sharp diffraction characteristic peaks that appeared at around $29^{\circ}$ and $47^{\circ}$ are the PVPCS/FHAp nanocomposites corresponding to the peaks of FHAp powder. The XRD patterns show diffraction peaks with high intensities, which confirms the nano size with crystalline nature (Meenakshi 
Sundaram et al. 2006; Murugan and Ramakrishna 2004; Neira et al. 2009).

FTIR analysis

The FTIR spectra of pure nano FHAp and PVPCS/FHAp nanocomposites are shown in Fig. 2. The $v_{2}$ phosphate stretching mode appeared at $465-486 \mathrm{~cm}^{-1}$ and corresponds to $\mathrm{PO}_{4}{ }^{3-}$ group in FHAp (Degirmenbasi et al. 2006). The bands that appeared at $1,042-1,070 \mathrm{~cm}^{-1}$ and $565-567 \mathrm{~cm}^{-1}$ correspond to different modes of the $\mathrm{PO}_{4}{ }^{3-}$ group in fluorinated hydroxyapatite (Yanbao et al. 2008). The band that appeared at $604 \mathrm{~cm}^{-1}$ corresponds to O-P$\mathrm{O}$ bending and $v_{1}$ symmetric $\mathrm{P}-\mathrm{O}$ stretching modes (Ma et al. 2006). The $v_{1}$ symmetric stretching mode of phosphate group is observed at $882 \mathrm{~cm}^{-1}$ (Zhang and Mild 2008). The observed band at $1,367 \mathrm{~cm}^{-1}$ is due to the stretching mode of carbonate, which may be due to the acquisition of air during mineral precipitation (Bertinetti et al. 2007). Similarly, the observed bands at 1,417 and $823-882 \mathrm{~cm}^{-1}$ are assigned to carbonate ions (Pan and Xiong 2009; Paulo et al. 2011; Pramanik et al. 2006, 2008). The lattice $\mathrm{H}_{2} \mathrm{O}$ exists in the range of $1,599-1,602 \mathrm{~cm}^{-1}$, while the bands observed at $3,411-3,432 \mathrm{~cm}^{-1}$ overlap the

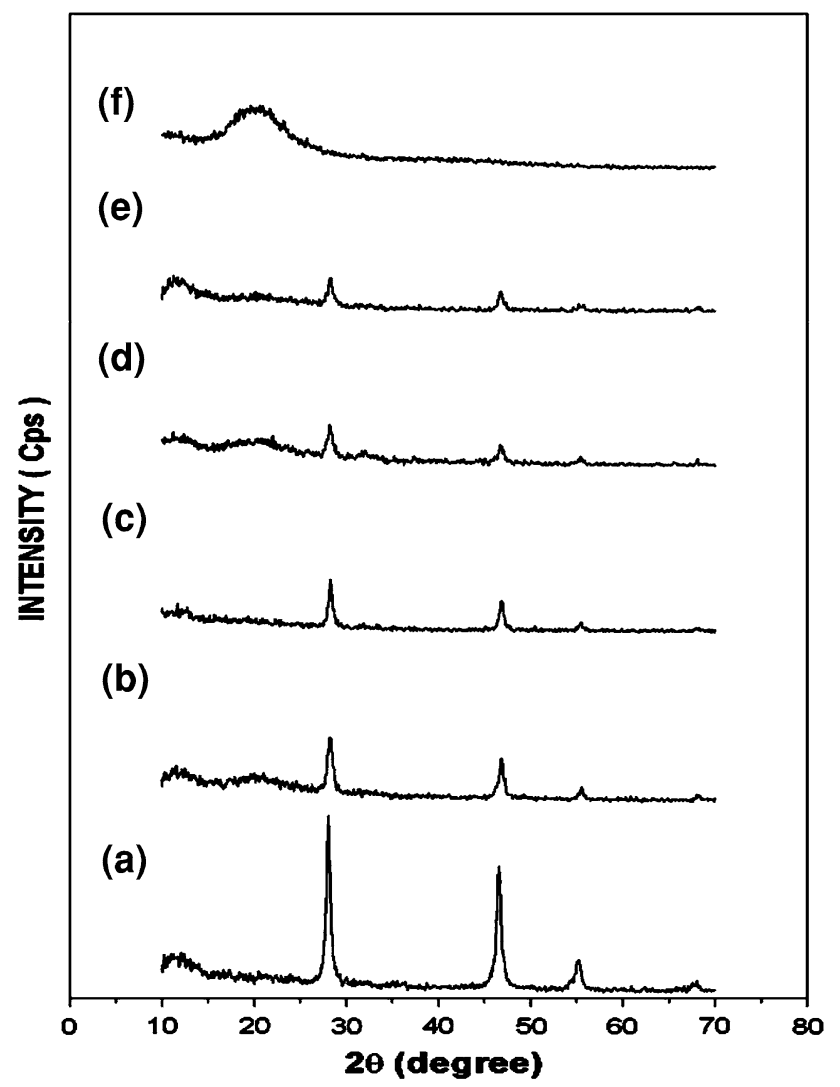

Fig. 1 XRD Pattern of a nano FHAp, b nano PVPCS20/FHAp, c nano PVPCS40/FHAp, d nano PVPCS60/FHAp and e nano PVPCS80/FHAp and f PVPCS
-OH group (Kannan and Ferreira 2006). The band observed between 2,926 and 2,929 $\mathrm{cm}^{-1}$ corresponds to C$\mathrm{H}$ stretching band of PVPCS (Murugan and Ramakrishna 2004). A new peak of stretching band is observed at $2,929 \mathrm{~cm}^{-1}$, when the PVPCS is added. This indicates the chemical bond interactions between FHAp and PVPCS. A new peak band that appears at $1,219-1,220 \mathrm{~cm}^{-1}$ corresponds to $\mathrm{F}^{-}$group in FHAp. The bands observed between 1,638 and $1,710 \mathrm{~cm}^{-1}$ and 1,270 and $1,271 \mathrm{~cm}^{-1}$ correspond to $\mathrm{C}=\mathrm{N}$ stretching band and $\mathrm{C}-\mathrm{N}$ band of PVPCS (Murugan and Ramakrishna 2004).

\section{FE-SEM analysis}

SEM images of pure nano FHAp and different weight percentages of PVPCS compositions are illustrated in Fig. 3. The SEM picture shows that particles exhibit nano rod morphology. The particle size of pure FHAp is in the range of $27-70 \mathrm{~nm}$. In case of composites, when the composition of PVPCS is added to FHAp, the rod-like morphology starts to disappear. The increase in the PVPCS compositions, i.e., 20, 40, $60 \mathrm{wt}$. \% leads to a corresponding change from rod-like to an irregular morphology. Further, it is evident that the particle size decreases with

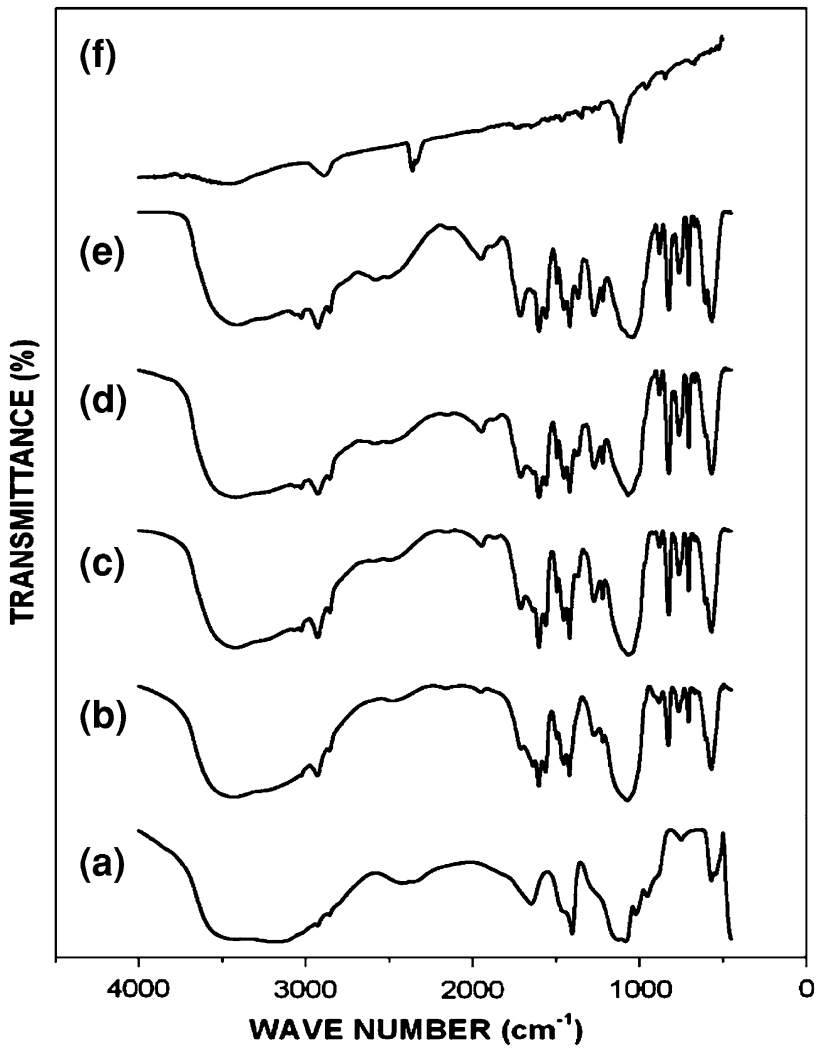

Fig. 2 FT-IR Spectra of a nano FHAp, b nano PVPCS20/FHAp, c nano PVPCS40/FHAp, d nano PVPCS60/FHAp and e nano PVPCS80/FHAp and f PVPCS 

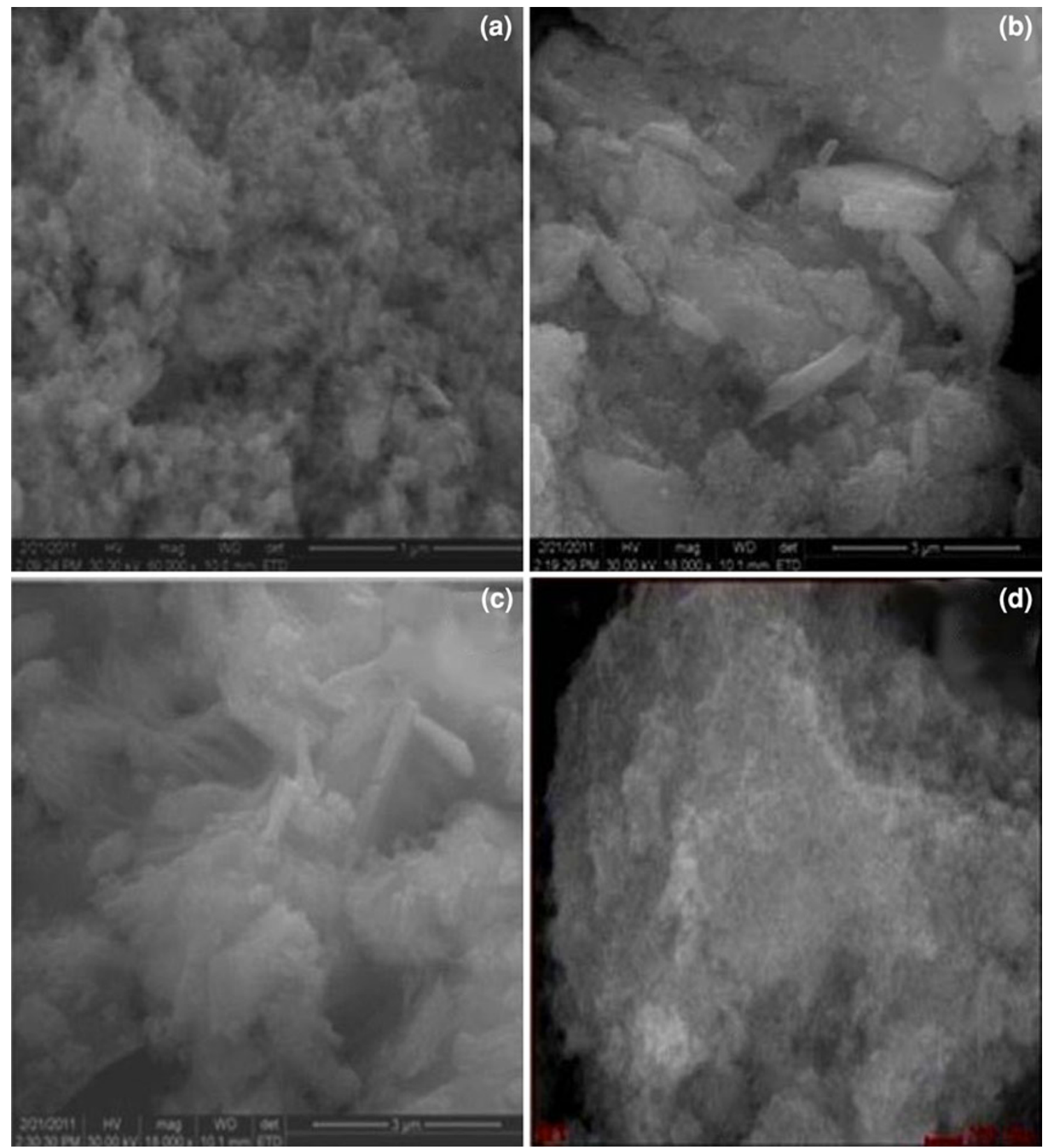

Fig. 3 FE-SEM images of a nano FHAp, b nano PVPCS20/FHAp, c nano PVPCS40/FHAp and d nano PVPCS60/FHAp

increase in PVPCS composition. The elemental analysis (EDAX) of nano PVPCS20/FHAp and nano PVPCS60/ FHAp can demonstrate similar composition as illustrated in Fig. 4. Mineral composition (calcium phosphate: $\mathrm{Ca}, \mathrm{O}, \mathrm{P}$ ) and organic content $(\mathrm{C})$ are present in both nanocomposites tested.

\section{HRTEM analysis}

Figure 5 shows the TEM photograph of nano PVPCS/ FHAp composite powder. The nano PVPCS/FHAp composite particles, shown in Fig. 5 are in nanometer scale.
Nano PVPCS/FHAp composite particles were a bit thicker (10-60 nm) and longer with clear contour. In addition the particles showed less agglomeration, and the selected area electron diffraction (SAED, in Fig. 5) of the precipitates shows diffraction ring or patterns, which implies that the precipitates are crystalline. This agrees with XRD results.

Thermo gravimetric analysis

The TGA (Fig. 6) of the PVPCS/FHAp nanocomposite powder was carried out between 50 and $1,400{ }^{\circ} \mathrm{C}$ in air at a heating rate of $20{ }^{\circ} \mathrm{C} / \mathrm{min}$. The decomposition behavior of 
Fig. 4 EDAX Spectrum of nano PVPCS60/FHAp

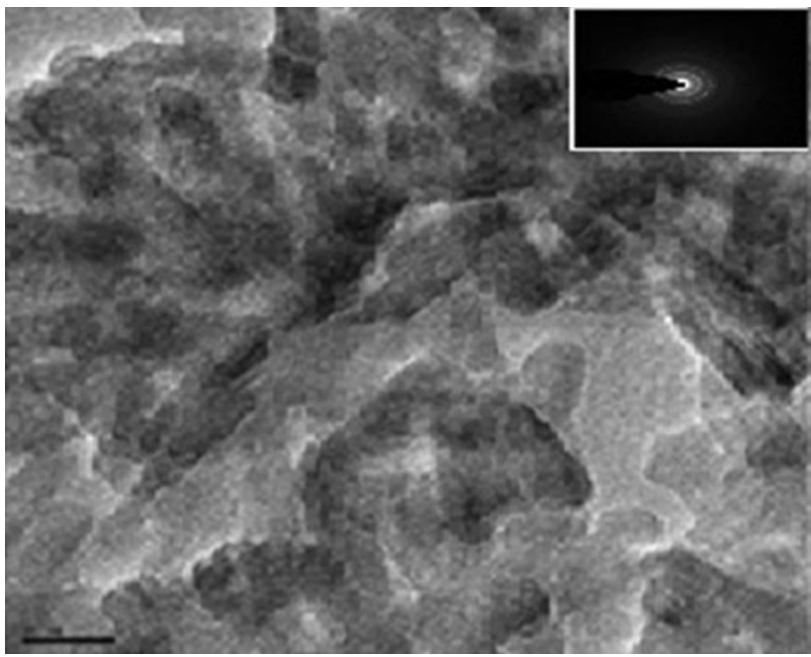

Fig. 5 HR TEM and SAED images of FHAp-PVPCS 20 nanocomposite

PVPCS/FHAp nanocomposite is shown in Fig. 6. The nano FHAp content is calculated from the residual weight in TGA curves at $600{ }^{\circ} \mathrm{C}$. However, since it is very difficult to control adsorbed water content in the composites, this nano FHAp content is only an approximate value. In the TGA curves several steps are observed (Rajendran et al. 2002; Singh et al. 2008; Wang et al. 2007). The first step, showing a small decrease in weight, is associated with adsorbed water-removing when heated above $90{ }^{\circ} \mathrm{C}$. The second step from 140 to $390{ }^{\circ} \mathrm{C}$ may be due to the dehydration reaction of $\mathrm{C}-\mathrm{OH}$ groups in PVPCS chains. This temperature shifts to a higher temperature, when the nano FHAp content increases. The third step was degradation of PVPCS matrix releasing $\mathrm{CO}_{2}$ gas. This temperature shifts to a lower temperature in the TG curves caused by the

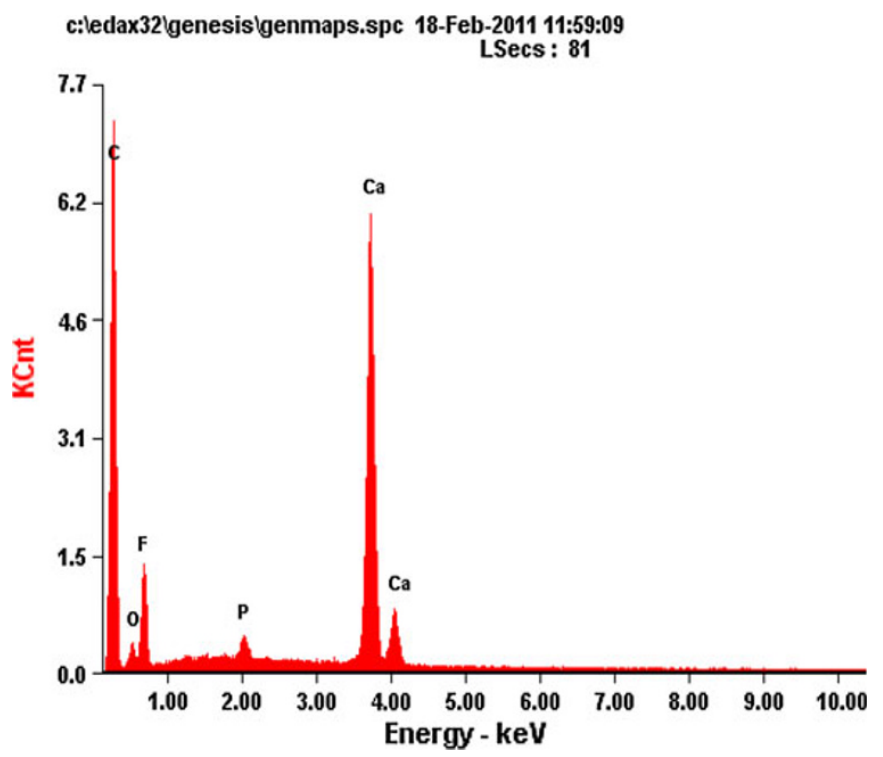

increasing nano FHAp content. The fact that the second step is initiated at slightly higher temperature and the third step occurs at slightly lower temperature than in pure PVPCS is suggestive of the presence of chemical interaction between PVPCS and the nano FHAp.

${ }^{31}$ P MAS-NMR analysis

The ${ }^{31} \mathrm{P}$ MAS-NMR spectra for the PVPCS/FHAp nanocomposite and nano FHAp powders are shown in Fig. 7. A distinctive resonance peak appears at $0.050 \mathrm{ppm}$ in Fig. 7 for the nano FHAp (Zhan et al. 2005; Zhang and Mild 2008; Zhang et al. 2003). After the development of PVPCS/FHAp nanocomposites, the ${ }^{31} \mathrm{P}$ characteristic peak moves to $1.902 \mathrm{ppm}$ as shown in Fig. 7a, indicating that after the formation of nanocomposites, the chemical environment of the phosphorus atom in nano FHAp crystal has been changed. This shift is due to the interaction of FHAp with PVPCS in PVPCS/FHAp nanocomposite. The chemical interaction may be due the hydrogen bonding interaction between the $\mathrm{PO}_{4}{ }^{3-}$ ions of FHAp and the $-\mathrm{OH}$ functional groups of PVPCS.

\section{Antimicrobial analysis}

The antifungal activity of the screening data for the composites are given in Table 1. It is observed from the results that PVPCS/FHAp nanocomposites show some antifungal activity. However, the PVPCS20/FHAp nanocomposite showed higher activity against the tested fungus at $1,000 \mu \mathrm{g} /$ $\mathrm{ml}$ concentration and other inoculums dilutions when compared with the other PVPCS/FHAp nanocomposite.

When the antibacterial activity was evaluated as shown in Table 1, all the PVPCS/FHAp composition of 
Fig. 6 TGA curve of nano PVPCS20/FHAp composite
TG $\%$

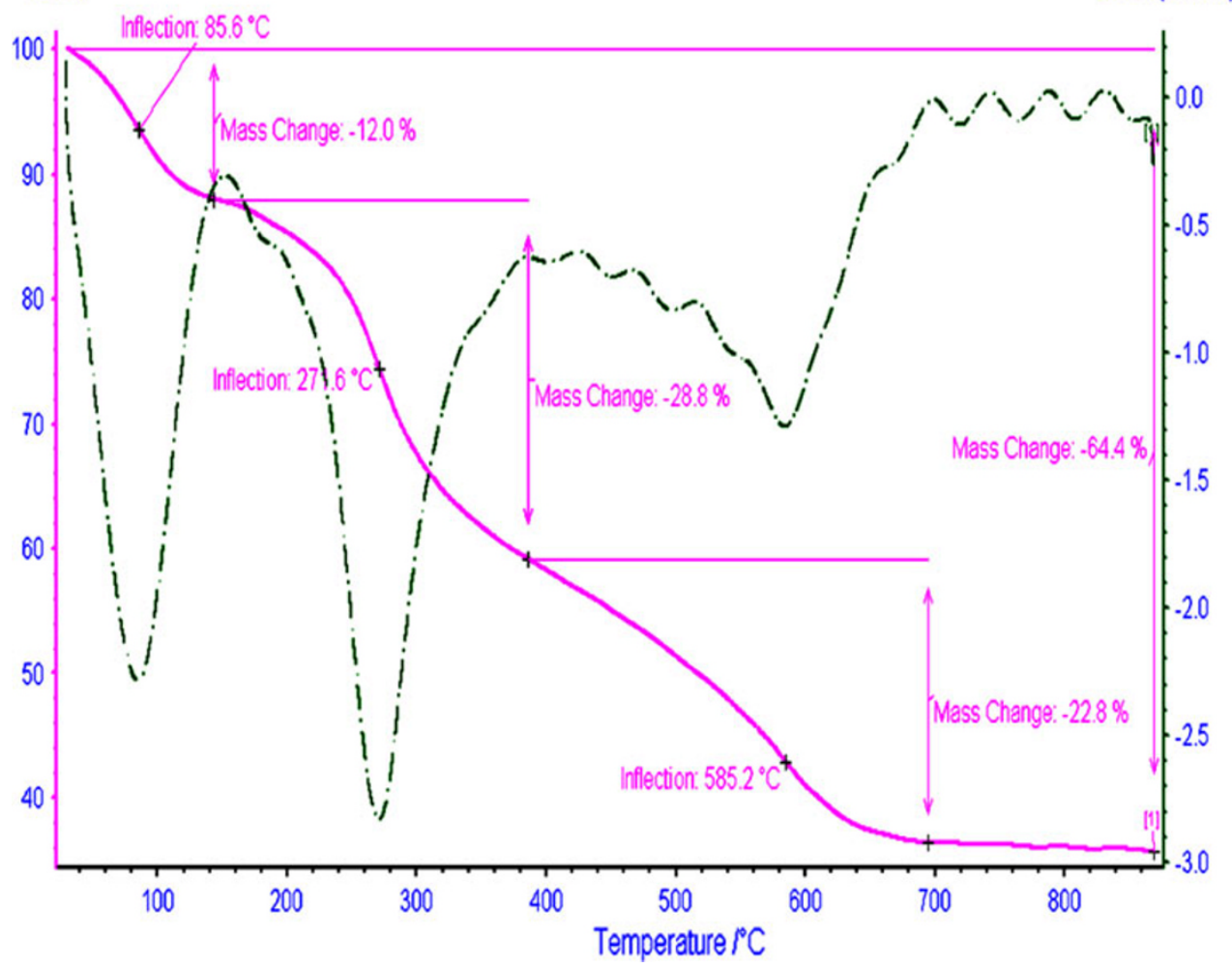

nanocomposites showed comparable activity against all the selected bacteria. From the data it is observed that at $1,000 \mu \mathrm{g} / \mathrm{ml}$ concentration, the composite of PVPCS40/ FHAp showed higher antibacterial activity against Salmonella typhi, Vibrio cholera, Escherichia coli, and Klebsiella pneumoniae. PVPCS20/FHAp showed higher antibacterial activity against Staphylococcus aureus. The antibacterial activity is dependent on the molecular structure of the compound, the solvent used, and the bacterial stain under consideration.
Anti-inflammatory potential analysis

The compound PVPCS20/FHAp and PVPCS 60/FHAp showed significant protection against HRBC membrane rupture which is induced by hypotonic saline (Wang et al. 2008; Wiria et al. 2008; Yang et al. 1997; Yanbao et al. 2008; OECD). The effect may be due to the resistance caused by polymers in the destruction of erythrocyte membrane. From the results it was proved that nano PVPCS20/FHAp composition was more effective than
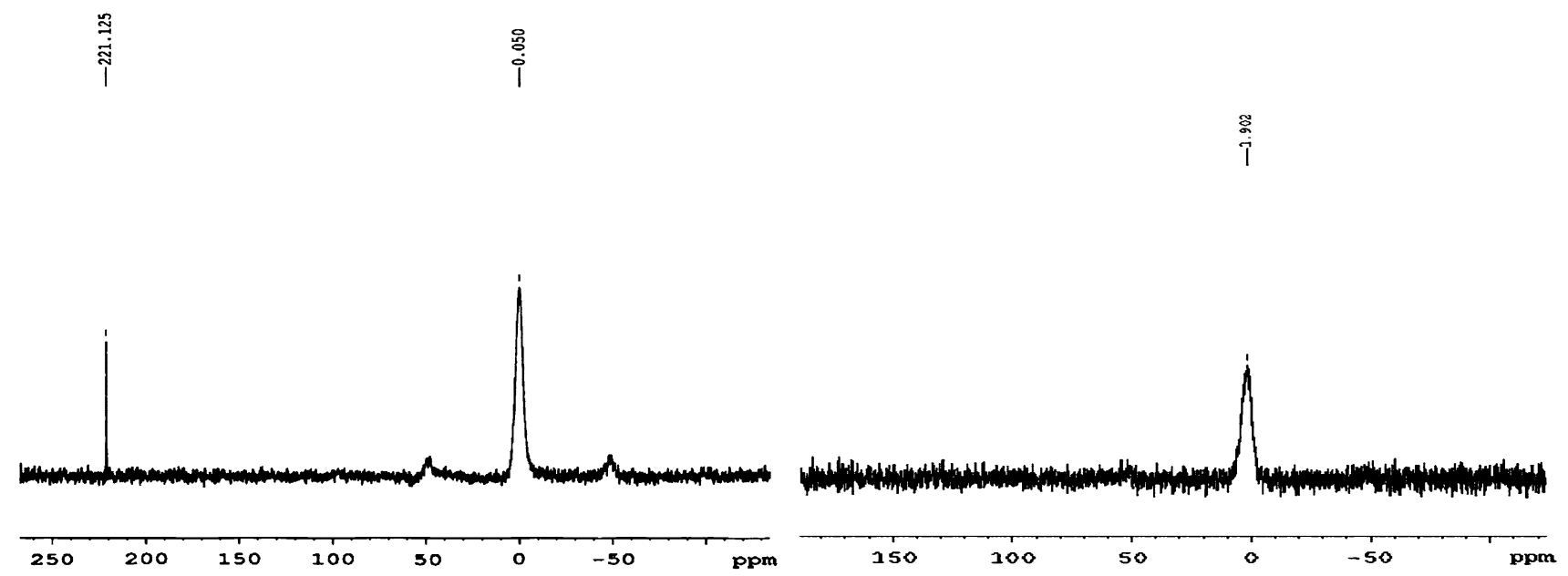

Fig. $7{ }^{31}$ P MAS-NMR Spectra of nano FHAp and (7a) ${ }^{31}$ P MAS-NMR Spectra of nano PVPCS40/FHAp composite 
Table 1 Antibacterial and antifungal activity of nano PVPCS/FHAp composites

\begin{tabular}{|c|c|c|c|c|c|c|c|c|c|c|c|c|}
\hline \multirow[t]{5}{*}{ Organism } & \multicolumn{12}{|c|}{ Sample name } \\
\hline & \multicolumn{12}{|c|}{ Representation of zone of inhibition (diameter in $\mathrm{mm}$ ) } \\
\hline & \multicolumn{3}{|c|}{$\begin{array}{l}\text { PVPCS 20/FHAp } \\
\text { nanocomposite }\end{array}$} & \multicolumn{3}{|c|}{$\begin{array}{l}\text { PVPCS 40/FHAp } \\
\text { nanocomposite }\end{array}$} & \multicolumn{3}{|c|}{$\begin{array}{l}\text { PVPCS 60/FHAp } \\
\text { nanocomposite }\end{array}$} & \multicolumn{3}{|c|}{$\begin{array}{l}\text { PVPCS 80/FHAp } \\
\text { nanocomposite }\end{array}$} \\
\hline & \multicolumn{3}{|c|}{ Concentration (in $\mu \mathrm{g} / \mathrm{ml}$ ) } & \multicolumn{3}{|c|}{ Concentration (in $\mu \mathrm{g} / \mathrm{ml}$ ) } & \multicolumn{3}{|c|}{ Concentration (in $\mu \mathrm{g} / \mathrm{ml}$ ) } & \multicolumn{3}{|c|}{ Concentration (in $\mu \mathrm{g} / \mathrm{ml}$} \\
\hline & 500 & 750 & 1000 & 500 & 750 & 1000 & 500 & 750 & 1000 & 500 & 750 & 1000 \\
\hline S. aureus & 11 & 12 & 13 & 11 & 11 & 11 & 11 & 11 & 11 & - & - & - \\
\hline S. typi & - & 11 & 12 & 13 & 14 & 15 & 12 & 13 & 13 & 13 & 14 & 14 \\
\hline E. coli & - & 11 & 12 & 13 & 13 & 14 & 11 & 13 & 14 & 11 & 12 & 13 \\
\hline V. cholerae & 11 & 12 & 11 & 11 & 12 & 14 & - & - & 11 & 11 & 12 & - \\
\hline K. pneumoniae & - & 12 & 12 & 11 & 15 & 17 & 12 & 11 & 11 & - & 12 & 15 \\
\hline C. albicans & 11 & 12 & 13 & - & 11 & 12 & - & 11 & 12 & 11 & 11 & 12 \\
\hline C. paratrophicalis & 11 & 12 & 12 & - & 11 & 12 & - & 11 & 11 & - & 11 & 11 \\
\hline
\end{tabular}

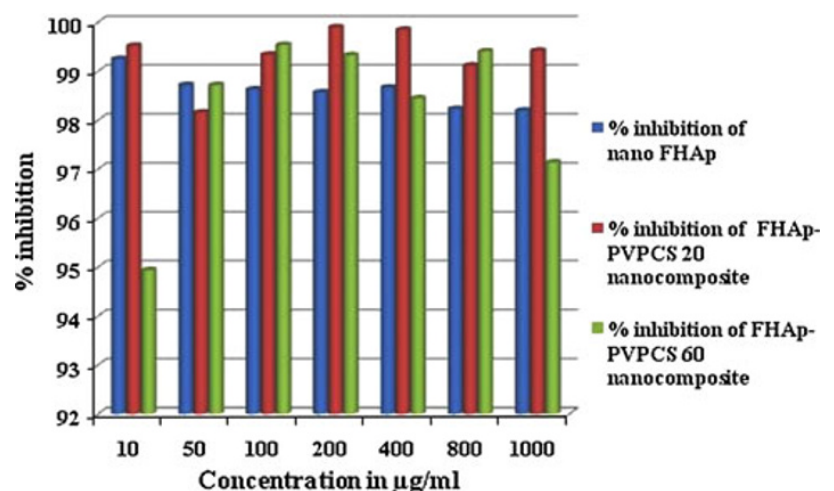

Fig. 8 Anti-inflammatory study of FHAp and PVPCS/FHAp nanocomposites

Table 2 Anti-inflammatory activity by HRBC membrane stabilization method

\begin{tabular}{llll}
\hline $\begin{array}{l}\text { Concentration } \\
\text { (in } \mu \mathrm{g} / \mathrm{ml})\end{array}$ & $\begin{array}{l}\text { \% inhibition } \\
\text { of nano } \\
\text { FHAp }\end{array}$ & $\begin{array}{l}\text { \% inhibition of } \\
\text { PVPCS 20/FHAp } \\
\text { nanocomposite }\end{array}$ & $\begin{array}{l}\text { \% inhibition of } \\
\text { PVPCS 60/FHAp } \\
\text { nanocomposite }\end{array}$ \\
\hline 10 & 99.25 & 99.52 & 94.94 \\
50 & 98.72 & 98.16 & 98.72 \\
100 & 98.63 & 99.34 & 99.54 \\
200 & 98.57 & 99.90 & 99.33 \\
400 & 98.67 & 99.85 & 98.45 \\
800 & 98.23 & 99.12 & 99.41 \\
\hline
\end{tabular}

nano PVPCS60/FHAp composition and also nano FHAp (Fig. 8; Table 2). Further work is in progress to identify the exact mechanism involved in anti inflammatory activity. Developing a biomaterial with good mechanical and biological properties and with perspective to act as a cell carrier of stem cells or differentiated cells is a challenge in regenerative medicine.
Evaluation of in vivo anti-inflammatory activity of PVPCS 40/nanoFHAp composite

Determination of lethal dose-50

The median lethal dose $\mathrm{LD}_{50}$ of the chemical compound was determined in male wistar rats using oral administration of PVPCS40/nano FHAp. The experiment was carried out in five groups for PVPCS40/nano FHAp composite of three animals per each group that were administered 100 , $250,500,1,000,2,000 \mathrm{mg} / \mathrm{kg}$ of extract respectively.

The animals were monitored for about $24 \mathrm{~h}$ and following parameters are noted in each group

1. Body weight

2. Any changes in skin, eyes

3. Somatomotor activity

Behavior patterns such as tremor, rigidity, convulsions, salivations, diarrhea, lethargy, sleep and coma.

There was no toxicity actions observed while examining the above parameters.

In vivo anti-inflammatory activity using sample-I (PVPCS 40/nanoFHAp) with carrageenan induced paw oedema in rat models

The mercury displacement method was used to determine the anti-inflammatory activity against carrageenan-induced paw odema. The animals were divided into four groups comprising six animals in each group.

The control groups were treated with carrageenan $0.1 \%$,the second group were treated with indomethacin $20 \mathrm{mg} / \mathrm{kg}$ i.p + carrageenan, and the third and fourth groups were treated with PVPCS 40/nano FHAp composite $125 \mathrm{mg} / \mathrm{kg}$ and $250 \mathrm{mg} / \mathrm{kg}+$ carrageenan Table 3 . 
Table 3 Measurement of paw volume in PVPCS 40/FHAp nanocomposite

\begin{tabular}{|c|c|c|c|c|c|c|c|}
\hline \multirow[t]{2}{*}{ S. no. } & \multirow[t]{2}{*}{ Groups } & \multirow[t]{2}{*}{ Animals } & \multirow{2}{*}{$\begin{array}{l}\text { Animals weight } \\
\text { (in gm) }\end{array}$} & \multicolumn{4}{|c|}{ Increase in paw volume } \\
\hline & & & & $15 \min (\mathrm{ml})$ & $30 \min (\mathrm{ml})$ & $45 \min (\mathrm{ml})$ & $60 \min (\mathrm{ml})$ \\
\hline \multirow[t]{7}{*}{1.} & \multirow[t]{6}{*}{ Control (carrageenan) } & 1 & 125 & 0.12 & 0.15 & 0.19 & 0.23 \\
\hline & & 2 & 150 & 0.14 & 0.16 & 0.18 & 0.22 \\
\hline & & 3 & 150 & 0.13 & 0.17 & 0.19 & 0.23 \\
\hline & & 4 & 175 & 0.15 & 0.18 & 0.19 & 0.22 \\
\hline & & 5 & 200 & 0.14 & 0.17 & 0.18 & 0.24 \\
\hline & & 6 & 150 & 0.15 & 0.16 & 0.20 & 0.23 \\
\hline & Average & & 158 & 0.13 & 0.16 & 0.18 & 0.22 \\
\hline \multirow[t]{7}{*}{2.} & \multirow[t]{6}{*}{ Indomethacin + Carrageenen } & 1 & 150 & 0.06 & 0.07 & 0.06 & 0.04 \\
\hline & & 2 & 230 & 0.05 & 0.05 & 0.05 & 0.06 \\
\hline & & 3 & 220 & 0.02 & 0.04 & 0.07 & 0.07 \\
\hline & & 4 & 210 & 0.03 & 0.05 & 0.08 & 0.08 \\
\hline & & 5 & 230 & 0.04 & 0.06 & 0.05 & 0.05 \\
\hline & & 6 & 220 & 0.05 & 0.05 & 0.06 & 0.07 \\
\hline & Average & & 210 & 0.04 & 0.05 & 0.07 & 0.06 \\
\hline \multirow[t]{7}{*}{3.} & Sample-II & 1 & 150 & 0.10 & 0.15 & 0.16 & 0.12 \\
\hline & \multirow[t]{5}{*}{$125 \mathrm{mg} / \mathrm{kg}+$ carrageenan } & 2 & 175 & 0.09 & 0.14 & 0.14 & 0.13 \\
\hline & & 3 & 150 & 0.11 & 0.14 & 0.14 & 0.12 \\
\hline & & 4 & 200 & 0.11 & 0.13 & 0.15 & 0.14 \\
\hline & & 5 & 210 & 0.10 & 0.12 & 0.14 & 0.13 \\
\hline & & 6 & 170 & 0.10 & 0.13 & 0.14 & 0.13 \\
\hline & Average & & 175 & 0.10 & 0.12 & 0.14 & 0.13 \\
\hline \multirow[t]{6}{*}{4.} & Sample-II & 1 & 250 & 0.08 & 0.14 & 0.13 & 0.12 \\
\hline & $250 \mathrm{mg} / \mathrm{kg}+$ carrageenan & 2 & 225 & 0.07 & 0.13 & 0.12 & 0.11 \\
\hline & & 3 & 225 & 0.06 & 0.12 & 0.13 & 0.13 \\
\hline & & 4 & 200 & 0.05 & 0.13 & 0.11 & 0.12 \\
\hline & & 5 & 210 & 0.06 & 0.12 & 0.14 & 0.14 \\
\hline & & 6 & 250 & 0.05 & 0.13 & 0.13 & 0.13 \\
\hline Average & & & 226 & 0.06 & 0.13 & 0.13 & 0.12 \\
\hline
\end{tabular}

\section{Conclusions}

In the present work, a novel PVPCS/FHAp nanocomposite is prepared by simple chemical route. The reduction in particle size with increase in concentration of PVPCS is due to the size control effect of PVPCS molecular structure. The rod-like morphology becomes as an irregular morphology with increase in PVPCS additives. It is inferred that the composition of PVPCS shows significant influence on particle size, thermal stability, and antimicrobial activities which facilitate to optimize the composition of composite for particular applications. Nanomaterials are greatly promising in the development of more valuable orthopedic and dental implants. However, the mechanism of interaction between PVPCS/nano FHAp and biologic systems should be investigated thoroughly in future and applied in studies using in vitro, in vivo and preclinical methodologies to validate its use for biomedical applications.
Acknowledgments The authors are grateful for the financial supports from the University Grants Commission and Council of Scientific and Industrial Research, New Delhi, India. The authors are grateful to Metha College of Pharmacy, Thuraipakkam, Chennai, Tamil Nadu, India.

Open Access This article is distributed under the terms of the Creative Commons Attribution License which permits any use, distribution, and reproduction in any medium, provided the original author(s) and the source are credited.

\section{References}

Bertinetti L, Tampieri A, Landi E, Ducati C, Midgley PA, Coluccia S, Martra G (2007) Surface structure, hydration and cationic sites of nanohydroxyapatite: UHR-TEM, IR, Microgravimetric studies. J Phys Chem C 111:4027-4035

Boissiere M, Meadows PJ, Brayner R, Helary C, Livage J, Coradin T (2006) Turning biopolymer particles into hybrid capsules: the example of silica/alginate nanocomposites. J Mater Chem 16:1178-1182 
Bose S, Saha SK (2003) Synthesis and characterization of hydroxyapatite nanopowders by emulsion technique. Chem Mater 15:4464-4469

Chen CW, Oakes CS, Byrappa K, Riman RE, Brown K, TenHuisen KS, Janas VF (2004) Synthesis, characterization, and dispersion properties of hydroxyapatite prepared by mechanochemicalhydrothermal methods. J Mater Chem 14:2425-2432

Chen DZ, Tang CY, Chan KC, Tsui CP, Yu PHF, Leung MCP, Uskokovic PS (2007) Dynamic mechanical properties and in vitro bioactivity of PHBHV/HA nanocomposite. Compos Sci Technol 67:1617-1626

Choi D, Kumta PN (2006) An alternative chemical route for the synthesis and thermal stability of chemically enriched hydroxyapatite. J Am Ceram Soc 89(2):444-449

Darder M, Lo'pez-Blanco M, Aranda P, Aznar AJ, Bravo J, RuizHitzky E (2006) Microfibrous chitosan-sepiolite nanocomposites. Chem Mater 18:1602-1610

Degirmenbasi N, Kalyon DM, Birinci E (2006) Biocomposites of nanohydroxyapatite with collagen and poly (vinyl alcohol). Colloids Surf B Biointer 48:42-49

Ding Y, Liu J, Wang H, Shen G, Yu R (2007) A piezoelectric immunosensor for the detection of $\alpha$-fetoprotein using an interface of gold/hydroxyapatite hybrid nanomaterial. Biomaterials 28:2147-2154

Gandhidasan R, Thamaraichelvan A, Baburaj S (1991) Anti inflammatory action of Lannea coromandelica by HRBC membrane stabilization. Fitoterapia 1:81-85

Huang F, Shen Y, Xie A, Zhu J, Zhang C, Li S, Zhu J (2007) Study on synthesis and properties of hydroxyapatite nanorods and its complex containing biopolymer. J Mater Sci 42:8599-8605

Joseph R, Tanner KE (2005) Effect of morphological features and surface area of hydroxyapatite on the fatigue behavior of hydroxyapatite-polyethylene composites. Biomacromolecules 6:1021-1026

Kannan S, Ferreira JMF (2006) Synthesis and thermal stability of hydroxyapatite- $\beta$ - tricalcium phosphate composites with cosubstituted sodium, magnesium, and fluorine. Chem Mater 18:198-203

Kannan S, Lemos AF, Ferreira JMF (2006) Synthesis and mechanical performance of biological-like hydroxyapatite. Chem Mater 18:2181-2186

Kawagoe K, Saito M, Shibuya T, Nakashima T, Hino K, Yoshikawa $\mathrm{H}$ (2000) Augmentation of cancellous screw fixation with hydroxyapatite composite resin (CAP) in vivo. J Biomed Mater Res 53:678-684

Kokubo T, Takadama H (2006) How useful is SBF in predicting in vivo bone bioactivity. Biomaterials 27:2907-2915

Komlev VS, Barinov SM, Rustichelli F (2003) Strength enhancement of porous hydroxyapatite ceramics by polymer impregnation. J Mater Sci Lett 22:1215-1217

Lak A, Mazloumi M, Mohajerani M, Kajbafvala A, Zanganeh S, Arami H, Sadrnezhaad SK (2008) Self-assembly of dandelion like hydroxyapatite nanostructures via hydrothermal method. J Am Ceram Soc 91(10):3292-3297

Li M, Xiao X, Liu R, Chen C, Huang L (2008) Structural characterization of zinc-substituted hydroxyapatite prepared by hydrothermal method. J Mater Sci Mater Med 19:797-803

Li J, Zuo Y, Cheng X, Yang W, Wang H, Li Y (2009) Preparation and characterization of nano-hydroxyapatite/polyamide 66 composite GBR membrane with asymmetric porous structure. J Mater Sci Mater Med 20:1031-1038

Ma MG, Zhu YJ, Chang J (2006) Monetite formed in mixed solvents of water and ethylene glycol and its transformation to hydroxyapatite. J Phys Chem B 110:14226-14230
Magaldi S, Mata-Essayag S, de Capriles CH, Perez C, Colella MT, Olaizola C, Ontiveros Y (2004) Int J Infect Dis 8:39-45

Meenakshi Sundaram N, Girija EK, Ashok M, Anee TK, Vani R, Suganthi R (2006) Crystallisation of hydroxyapatite nanocrystals under magnetic field. Mater Lett 60:761-765

Murugan R, Ramakrishna S (2004) Bioresorbable composite bone paste using polysaccharide based nano hydroxyapatite. Biomaterials 25:3829-3835

Neira IS, Kolen'ko YV, Lebedev OI, Tendeloo GV, Gupta HS, Guitian F, Yoshimura M (2009) An effective morphology control of hydroxyapatite crystals via hydrothermal synthesis. Cryst Growth Des 9(1):466-474

Pan Y, Xiong D (2009) Friction properties of nano-hydroxyapatite reinforced poly(vinyl alcohol) gel composites as an articular cartilage. Wear 266:699-703

Paulo AO et al (2011) Repair of critical-size defects with autogenous periosteum-derived cells combined with bovine an organic apatite/collagen: an experimental study in rat calvaria. Braz Dent J 22:322-328

Pramanik N, Bhargava P, Alam S, Pramanik P (2006) Processing and properties of nano-and macro-hydroxyapatite/poly (ethylene coacrylic acid) composites. Polym Compos 27:633-641

Pramanik N, Mohapatra S, Alam S, Pramanik P (2008) Synthesis of hydroxyapatite/poly(vinyl alcohol phosphate) nanocomposite and its characterisation. Polym Compos 29:429-436

Rajendran V, Nishara Begum A, Azooz MA, EI Bata FH (2002) Microstructural dependence on relevant physical-mechanical properties on $\mathrm{SiO}_{2}-\mathrm{Na}_{2} \mathrm{O}-\mathrm{CaO}-\mathrm{P}_{2} \mathrm{O}_{5}$ biological glasses. Biomaterials 23:4263-4275

Singh MK, Shokuhfar T, Almeida Gracio JJD, Sousa ACMD, Fereira F, Garmestani H, Ahzi S (2008) Hydroxyapatite modified with carbon-nanotube-reinforced poly(methyl methacrylate): a nanocomposite material for biomedical applications. Adv Funct Mater 18:694-700

Wang H, Li Y, Zuo Y, Li J, Ma S, Cheng L (2007) Biocompatibility and osteogenesis of biomimetic nanohydroxyapatite/polyamide composite scaffolds for bone tissue engineering. Biomaterials 28:3338-3348

Wang M, Li Y, Wu J, Xu F, Zuo Y, Jansen JA (2008) In vitro and in vivo study to the biocompatibility and biodegradation of hydroxyapatite/poly(vinyl alcohol)/gelatin composite. J Biomed Mater Res Part A 85:418-426

Wiria FE, Chua CK, Leong KF, Quah ZY, Chandrasekaran M, Lee MW (2008) Improved biocomposite development of poly (vinyl alcohol) and hydroxyapatite for tissue engineering scaffold fabrication using selective laser sintering. J Mater Sci Mater Med 19:989-996

Yanbao L, Dongxu L, Weng W (2008) Preparation of nano carbonatesubstituted hydroxyapatite from an amorphous precursor. Int $\mathbf{J}$ Appl Ceram Technol 5(5):442-448

Yang JM, Lu CS, Hsu YG, Shih CH (1997) Mechanical properties of acrylic bone cement containing $\mathrm{PMMA}-\mathrm{SiO}_{2}$ hybrid solgel material. J Biomed Mater Res 38:143-154

Zhan J, Tseng YH, Chan JCC (2005) Adv. Funct Mater 15:2005-2009

Zhang Y, Mild JLA (2008) Efficient biomimetic synthesis of rodlike hydroxyapatite particles with a high aspect ratio using polyvinylpyrrolidone as capping agent. Cryst Growth Des 8(7):2101-2107

Zhang W, Liao SS, Cui FZ (2003) Hierarchical self-assembly of nano-fibrils in mineralized collagen. Chem Mater 15:3221-3226

(2001) OECD Guide lines 423 acute toxicity studies 